\title{
SECM study of hydrogen photogeneration in a 1,2-dichloroethane | water biphasic system with decamethylruthenocene electron donor regeneration
}

\author{
Justyna Jedraszko ${ }^{\mathrm{a}}$, Wojciech Adamiak ${ }^{\mathrm{a}}$, Wojciech Nogala ${ }^{\mathrm{a}}$, Hubert H. Girault ${ }^{\mathrm{b}}$, Marcin Opallo ${ }^{\mathrm{a}, *}$ \\ a Institute of Physical Chemistry, Polish Academy of Sciences, ul. Kasprzaka 44/52, 01-224 Warszawa, Poland \\ b EPFL Valais Wallis, EPFL SB ISIC LEPA, Rue de l'Industrie 17, Case postale 440, CH-1951 Sion, Switzerland
}

\section{A R T I C L E I N F O}

\section{Keywords:}

Hydrogen evolution reaction (HER)

ITIES

Decamethylruthenocene

1,2-Dichloroethane

Water splitting

Scanning electrochemical microscopy (SECM)

\begin{abstract}
A B S T R A C T
This paper reports light driven hydrogen evolution reaction (HER) at 1,2-dichloroethane $\mid$ water (DCE $\mid$ W) interface using photoexcited decamethylruthenocene (DMRc) as electron donor. DMRc is in situ regenerated by electroreduction of its oxidized form $\left(\mathrm{DMRc}^{+}\right)$formed during HER as a by-product. This enables continuous HER using small amount of DMRc. Proton transfer from the acidic aqueous phase to the DCE phase is ensured by negative chemical polarization of the liquid|liquid interface. The reduction of protons in DCE occurs only after excitation of DMRc by light. Voltammetry performed with the organic droplet-modified glassy carbon electrode immersed in the aqueous electrolyte solution of various anions, indicated that oxidation of DMRc is followed by an anion insertion from water into the organic phase. We demonstrate that DMRc can be electrochemically regenerated at the microelectrode positioned close to the interface between two immiscible electrolyte solutions (ITIES) by the scanning electrochemical microscopy. Regeneration of the electron donor allows further development of biphasic system towards continuous hydrogen generation platform.
\end{abstract}

\section{Introduction}

Generation of $\mathrm{H}_{2}$ using metallocenes and their derivatives as electron donors has been studied since the late 1980s. The uses of ferrocene derivatives [1], decamethylferrocene [2], cyclopentadienylcobalt phosphine [3], cobaltocene [4], molybdocene [5], osmocene [6] or ruthenocene [7] as electron donors for hydrogen evolution reaction (HER) have been reported. In the case of osmocene and ruthenocene, the HER was carried out under light exposure.

Recently, it has been shown that light driven HER also occurs at a polarized ITIES in the presence of decamethylruthenocene (DMRc) [7]. DMRc due to its only moderately low redox potential is thermodynamically a weak electron donor for HER, however, in the presence of UV light it is capable to reduce protons dissolved in DCE [7-9]. Therefore, polarization of the liquid|liquid interface, ensuring transfer of protons from the acidic aqueous solution to DCE, is a key step of HER at ITIES. This can be done by chemical polarization of ITIES, e.g. by dissolving a salt with highly hydrophobic tetrakis(pentafluorophenyl) borate anion $\left(\mathrm{TB}^{-}\right)$in both phases [10-18]. For equimolar concentration of $\mathrm{TB}^{-}$in both phases, Galvani potential difference, $\Delta_{\mathrm{W}}{ }^{\mathrm{DCE}} \varphi$, between the two immiscible liquids is equal to $\Delta_{\mathrm{W}}{ }^{\mathrm{DCE}} \varphi_{\mathrm{TB}-}{ }^{\circ}=-0.69 \mathrm{~V}$ [19]. This is lower than the standard transfer potential of $\mathrm{H}^{+}$ $\left(\Delta_{\mathrm{W}}{ }^{\mathrm{DCE}} \varphi_{\mathrm{H}^{+}}{ }^{\circ}=-0.55 \mathrm{~V}\right)[10,20]$, which means that the protons spontaneously transfer from the water phase to the DCE phase. In this process, the $\mathrm{TB}^{-}$ion also acts as a phase transfer catalyst. $\mathrm{H}^{+}$can be transferred to DCE in the form of HTB, which then undergoes partial dissociation in the organic phase [13]. Inside the organic phase, the metallocene hydride [DMRc- $\left.\mathrm{H}^{+}\right][7,8]$ intermediate is formed through $\mathrm{H}^{+}$coordination to the metal atom. Upon light exposure, [DMRc-H] ${ }^{+}$ transforms to $\mathrm{DMRc}^{+}$and hydrogen which can partially dissolve in both phases [8]:

$$
\begin{aligned}
& 2 \mathrm{DMRc}_{(\mathrm{DCE})}+2 \mathrm{H}_{(\mathrm{w})}^{+}+2 \mathrm{~TB}_{(\mathrm{w})}^{-} \rightarrow 2[\mathrm{DMRc}-\mathrm{H}]_{(\mathrm{DCE})}^{+}+2 \mathrm{~TB}_{(\mathrm{DCE})}^{-} \\
& \stackrel{\text { light }}{\longrightarrow} 2 \mathrm{DMRc}_{(\mathrm{DCE})}^{+}+\mathrm{H}_{2} \uparrow+2 \mathrm{~TB}_{(\mathrm{DCE})}^{-}
\end{aligned}
$$

Electrochemical activity of DMRc ${ }^{+}$in DCE opens up the possibility of DMRc regeneration through electrochemical reduction. Concurrent regeneration of DMRc during light-driven HER can increase the efficiency of the hydrogen production and allow to perform the reaction continuously with a small volume of the organic phase, e.g. by using the electrode covered with microdroplet array. Then amount of generated $\mathrm{H}_{2}$ is not limited by amount of available molecular electron donor or its diffusion [21]. So far, electrochemical regeneration of $\mathrm{DMRc}^{+}$has been reported only in DCE single-phase system, where protons were initially present in the form of HTB acid [7]. Still, there is no report on DMRc ${ }^{+}$ regeneration in any biphasic system, where protons are not initially

\footnotetext{
* Corresponding author.

E-mail address: mopallo@ichf.edu.pl (M. Opallo).
} 
present in organic phase, but are pumped across the chemically polarized ITIES.

Here, we demonstrate an in situ regeneration of DMRc in the DCE |W biphasic system with the electrode positioned in organic phase close to the liquid|liquid interface by SECM. As a result of DMRc regeneration, the electron donor is not anymore sacrificial and the biphasic system can be further developed towards continuous low potential HER. To analyze the progress of the light-driven HER, colourimetry, potentiometry and voltammetry were used. In order to understand the ion transfer processes coupled to redox process of DMRc, voltammetry with the organic droplet-modified glassy carbon (GC) electrode was performed.

\section{Experimental}

\subsection{Chemicals}

DMRc (99\%) was obtained from ABCR. $\mathrm{NaClO}_{4}$ was purchased from Fluka. $\mathrm{NaCl}, \mathrm{KNO}_{3}, \mathrm{KPF}_{6}$, and DCE were from Sigma-Aldrich. Bis(triphenylphosphoranylidene)ammonium tetrakis(pentafluorophenyl)borate (BATB) was prepared by metathesis of bis(triphenylphosphoranylidene) ammonium chloride (Sigma-Aldrich) and lithium tetrakis(pentafluorophenyl)borate (LiTB, ABCR) [20], and recrystallized twice from acetone. Aqueous solutions were prepared with demineralized and filtered water from ELIX system (Millipore). Argon (N5.0) was from Multax.

\subsection{Apparatus and procedures}

Interfacial reaction was performed in bottles through $60 \mathrm{~min}$ with stirring of DCE phase using magnetic stirrer $(500 \mathrm{rpm})$. The volumes of DCE and W phases were $750 \mu \mathrm{l}$ each, and internal diameter of the flasks was $8 \mathrm{~mm}$.

Cyclic voltammetry and square wave voltammetry (SWV) with GC (disc $2 \mathrm{~mm}$ diameter, nLab) modified by the organic droplet were performed with CHI900B Electrochemical Workstation $(\mathrm{CH}$ Instruments). In the experiments with droplet-modified electrode, the GC electrode was used as a working electrode. Pt wire was used as counter electrode. $\mathrm{Ag} / \mathrm{AgCl}$ wire immersed in DCE phase or $\mathrm{Ag}|\mathrm{AgCl}| \mathrm{KCl}_{(3 \mathrm{M})}$ electrode in aqueous phase were used as reference electrodes.

SECM measurements were carried out with CHI900B SECM workstation ( $\mathrm{CH}$ Instruments). Pt microelectrodes for SECM experiments were made by sealing a Pt wire $(25 \mu \mathrm{m}$ diameter, Goodfellow, or $100 \mu \mathrm{m}$ diameter, Mint of Poland) using PC-10 micropipette puller (Narishige) into borosilicate glass capillaries and polished. Pt $-25 \mu \mathrm{m}$ and $100 \mu \mathrm{m}$ diameter disk microelectrodes were used as working electrodes in aqueous and organic solution, respectively. The larger microelectrode immersed in organic phase was fixed upward at the bottom of the cell. Pt wire and $\mathrm{Ag}|\mathrm{AgCl}| \mathrm{KCl}_{(3 \mathrm{M})}$ were counter and reference electrodes respectively, and were immersed in the aqueous phase. Position of Pt ( $25 \mu \mathrm{m}$ diameter) was controlled by stepper motors in the $\mathrm{X}, \mathrm{Y}$, and $\mathrm{Z}$ directions. All working electrodes were polished with $1,0.3$, and $0.05 \mu \mathrm{m}$ alumina and sonicated in ethanol and demineralized water. In analysis of open circuit potential $\left(E_{\mathrm{OCP}}\right)$ measurements all potentials were recalculated versus the potential of the reversible hydrogen electrode (RHE), determined as the potential of a Pt electrode being in contact with hydrogen bubbles under atmospheric pressure and used electrolyte ( $-276 \mathrm{mV}$ vs. $\mathrm{Ag} \mid \mathrm{AgCl}$ in $0.1 \mathrm{M} \mathrm{HClO}_{4}$ ). All solutions (except these used for ion transfer measurements) were deaerated by purging argon for $30 \mathrm{~min}$ before experiments. To maintain an anaerobic condition of the reaction, the electrochemical cell used in SECM experiments were inserted into a taller and wider beaker covered tightly with a parafilm with a little hole for SECM tip. Then, humidified Ar $\left(\mathrm{O}_{2}<1 \mathrm{ppm}\right)$ was delivered to the bottom of the beaker. Twophase reactions were performed in a glove box (Labconco) under Ar
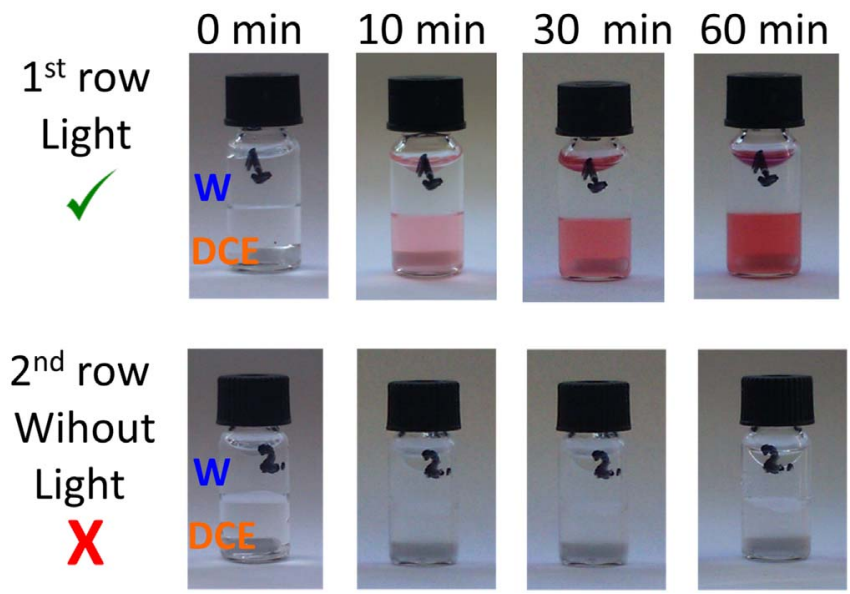

Fig. 1. Photographs demonstrating progress of the two-phase reaction carried out under exposure to xenon lamp light (1st row) or kept in darkness (2nd row). In all bottles, the water phase (upper phase) contains a $5 \mathrm{mmol} \mathrm{dm}^{-3} \mathrm{LiTB}$ in $0.1 \mathrm{~mol} \mathrm{dm}^{-3} \mathrm{HClO}_{4}$, and the bottom organic phase contains $5 \mathrm{mmol} \mathrm{dm}^{-3}$ of DMRc and $5 \mathrm{mmol} \mathrm{dm}{ }^{-3}$ BATB in DCE. The content of bottles was stirred with a magnetic stirrer $(500 \mathrm{rpm})$. Photographs were taken just after contacting the two phases $(0 \mathrm{~min})$ and after 10, 30 and $60 \mathrm{~min}$.

atmosphere. For the experiments with UV-light, a $150 \mathrm{~W}$ xenon lamp (Instytut Fotonowy Sp. z o.o., Poland) was applied. Electrochemical measurements were carried out in a grounded Faraday cage. All measurements were performed at room temperature $\left(22 \pm 2{ }^{\circ} \mathrm{C}\right)$.

\section{Results and discussion}

\subsection{Colourimetric, potentiometric and voltammetric study of light-driven HER at ITIES}

First, progress of the interfacial $\mathrm{H}_{2}$ photogeneration was monitored colourimetrically (Fig. 1) and potentiometrically (Fig. 2) to verify that this process occurs with a less powerful xenon lamp than reported earlier [8]. The DMRc solution in DCE is colourless (Fig. 1, see bottom phase in 1st column - at $0 \mathrm{~min}$ ). This solution strongly absorbs light in the ultraviolet range below $375 \mathrm{~nm}$ wavelength [8]. After two-phase reaction, under the exposure to a xenon lamp, solution turns pink, what is associated with the presence of an oxidized form of DMRc, due to strong absorption band with the maximum wavelength of $500 \mathrm{~nm}$ [8] (Fig. 1, see bottom phase in 1st row after 10, 30 and $60 \mathrm{~min}$ ). In the control experiment carried out in a black cardboard box, no colour change is observed during the stirring of both phases (Fig. 1, bottom phase in 2nd row). Also, the colour intensity of the organic phase (Fig. 1, 1st row) increases with time [8]. All these observations demonstrate that photo-HER at ITIES occurs when ITIES are polarized by the presence of $\mathrm{TB}^{-}$anions in both liquid phases and in the presence of UV light.

Estimation of local $\mathrm{H}_{2}$ concentration in aqueous phase, $\left[\mathrm{H}_{2}\right]$, was performed by potentiometry with Pt microelectrode ( $100 \mu \mathrm{m}$ diameter). Its value was calculated from $E_{\mathrm{OCP}}$ of this cell versus the RHE using the following equation $[13,22]$ :

$$
\left[\mathrm{H}_{2}\right]=\frac{\exp \left(-\frac{2 \mathrm{~F} E_{\mathrm{OCP}}}{\mathrm{RT}}\right)}{k_{H}}
$$

wherein $k_{H}$ is Henry's constant $\left(1282 \mathrm{dm}^{3} \mathrm{~mol}^{-1} \mathrm{~atm}\right)$ [23].

The $E_{\mathrm{OCP}}$ measured over $60 \mathrm{~s}$ after $60 \mathrm{~min}$ of the two-phase reaction performed under UV light exposure (the same system as in the Fig. 1, 1st row, $60 \mathrm{~min}$ ) is close to $20 \mathrm{mV}$ vs. RHE (Fig. 2A, red curve). Following Eq. (2), one can calculate $\left[\mathrm{H}_{2}\right]$ in the water phase and plot $\left[\mathrm{H}_{2}\right]$ vs. time dependence (Fig. $2 \mathrm{~B}$, red curve). Average $\left[\mathrm{H}_{2}\right]$ reaches $154 \mu \mathrm{mol} \mathrm{dm}{ }^{-3}$.

On the contrary, $E_{\mathrm{OCP}}$ measured in solution collected after control 

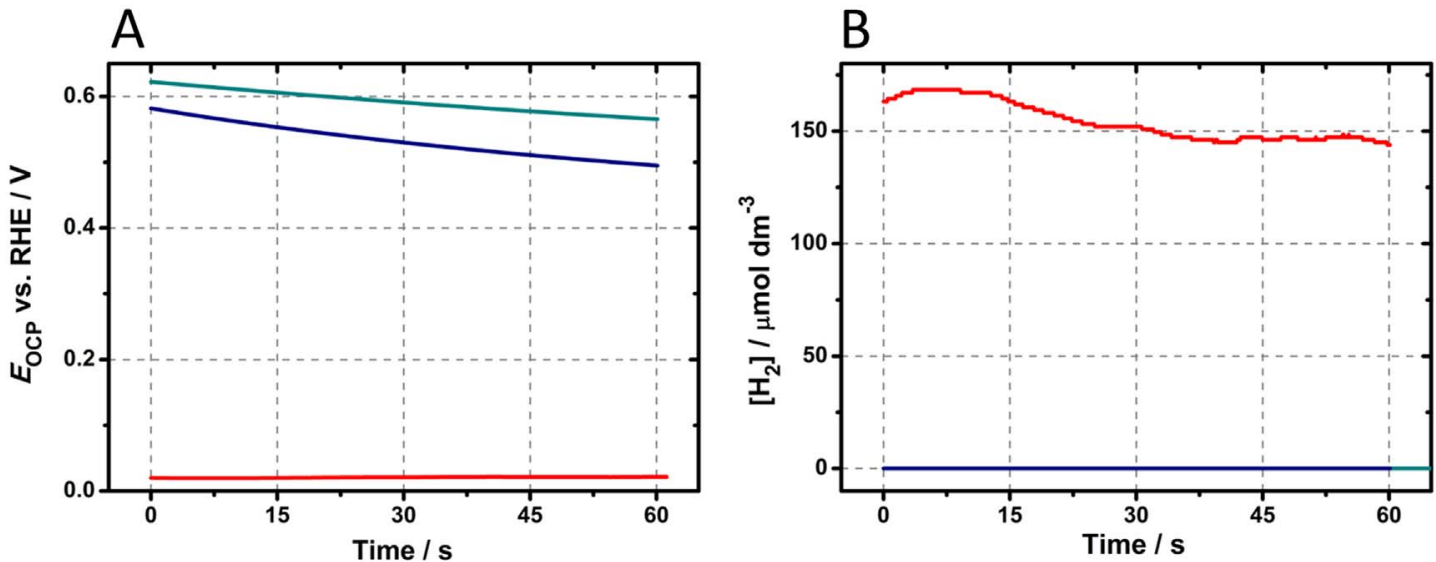

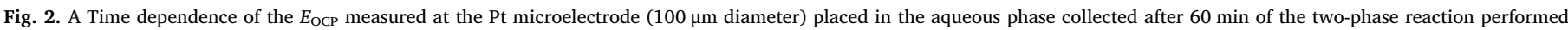

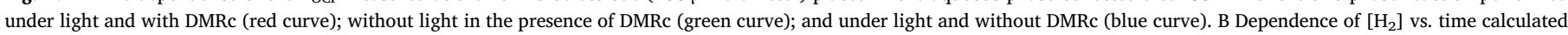
from the data shown in A. (For interpretation of the references to colour in this figure legend, the reader is referred to the web version of this article.)

experiments is above $0.5 \mathrm{~V}$ (Fig. 2A, blue and green curve), indicating the absence of hydrogen in the aqueous phase. Clearly, in the absence of light or DMRc, HER doesn't occur. These results also confirm that the colour change of the organic phase observed in (Fig. 1, 1st row), is due to the presence of DMRc ${ }^{+}$formed during the photogeneration of $\mathrm{H}_{2}$.

The progress of light-driven HER was also followed by cyclic voltammetry in the organic phase and the aqueous phase (Fig. 3). The blue curve in Fig. 3A results from oxidation of the DMRc in DCE and indicates the initial absence of dissolved DMRc ${ }^{+}$. After 60 min of the twophase reaction carried out under light, there is only a cathodic wave (Fig. 3A, red curve), corresponding to reduction of the photo-generated $\mathrm{DMRc}^{+}$. Residual anodic signal after the reaction indicates that DMRc almost completely reacted with protons in the organic phase. The cathodic signal is smaller than the anodic one probably due to partial transfer of $[\mathrm{DMRc}-\mathrm{H}]^{+}$from DCE to aqueous phase [8]. The grey curve was recorded for the two-phase system without DMRc in DCE (Fig. 3A, blank experiment). The cathodic current below $-0.27 \mathrm{~V}$ is probably due to electrochemical reduction of $\mathrm{H}^{+}$in DCE, which confirms the proton transfer mechanism.

Cyclic voltammogram recorded in the aqueous phase has a characteristic shape for the Pt microelectrode in the acidic aqueous solution (Fig. 3B, blue curve). After $60 \mathrm{~min}$ of the two-phase photo-reaction, an increase of anodic current above $-0.2 \mathrm{~V}$ (red curve, Fig. 3B), clearly confirms presence of $\mathrm{H}_{2}$ in aqueous phase. This result agrees well with potentiometric experiments that show the presence of photo-generated $\mathrm{H}_{2}$ in the two-phase system (see above).

\subsection{Study of ion transfer at DCE $\mid$ water interface with organic droplet modified GC electrode}

Oxidation of DMRc in the organic phase leads to formation of a positive charge, which must be compensated through the anion transfer from the aqueous phase to DCE or cation expulsion from DCE to water. To find which process dominates, a SWV was performed in a threeelectrodes cell (Fig. 4A) with the organic droplet modified GC electrode $[24,25]$.

Organic droplet consists of DMRc and BATB solution in DCE. The electrode was immersed into an aqueous solution of various electrolytes, and so the ITIES was formed at the droplet|aqueous electrolyte solution boundary. As shown in Fig. 4 the SWV peak potential, $E_{\mathrm{p}}$, depends on the nature of the aqueous electrolyte anion, i.e. for more hydrophobic anions like $\mathrm{ClO}_{4}{ }^{-}$or $\mathrm{PF}_{6}{ }^{-}$it is more negative than for more hydrophilic anions like $\mathrm{NO}_{3}{ }^{-}$or $\mathrm{Cl}^{-}$. The value of $E_{\mathrm{p}}$ is linearly dependent on the standard Gibbs transfer potential (Fig. 4B) with a slope close to unity (0.92).

This clearly indicates that electroneutrality of DCE phase upon DMRc oxidation is maintained by the anion $\left(\mathrm{A}^{-}\right)$transfer from water to the organic phase [24]:

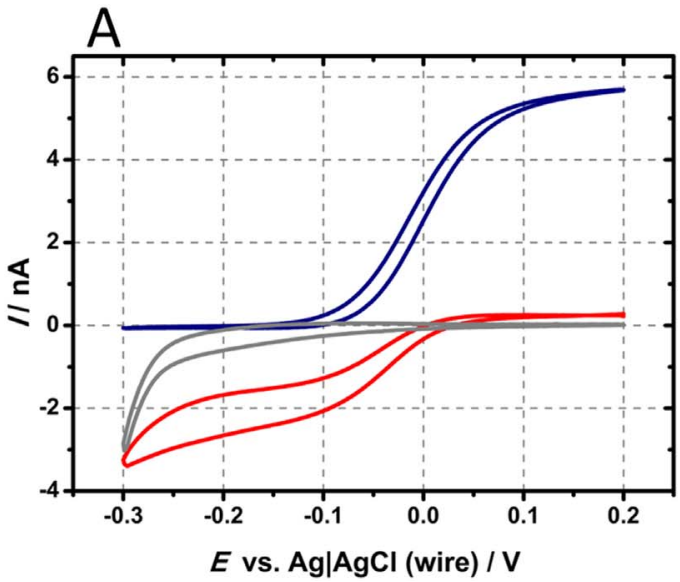

B

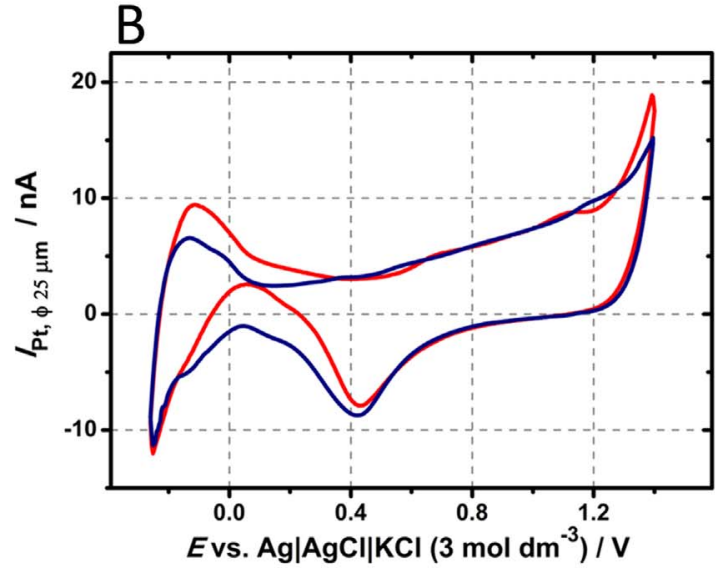

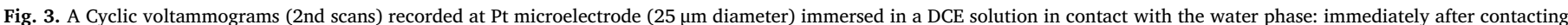

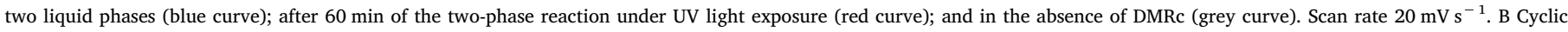

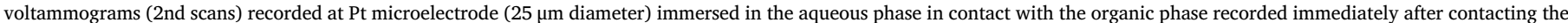

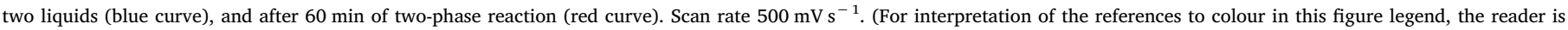
referred to the web version of this article.) 

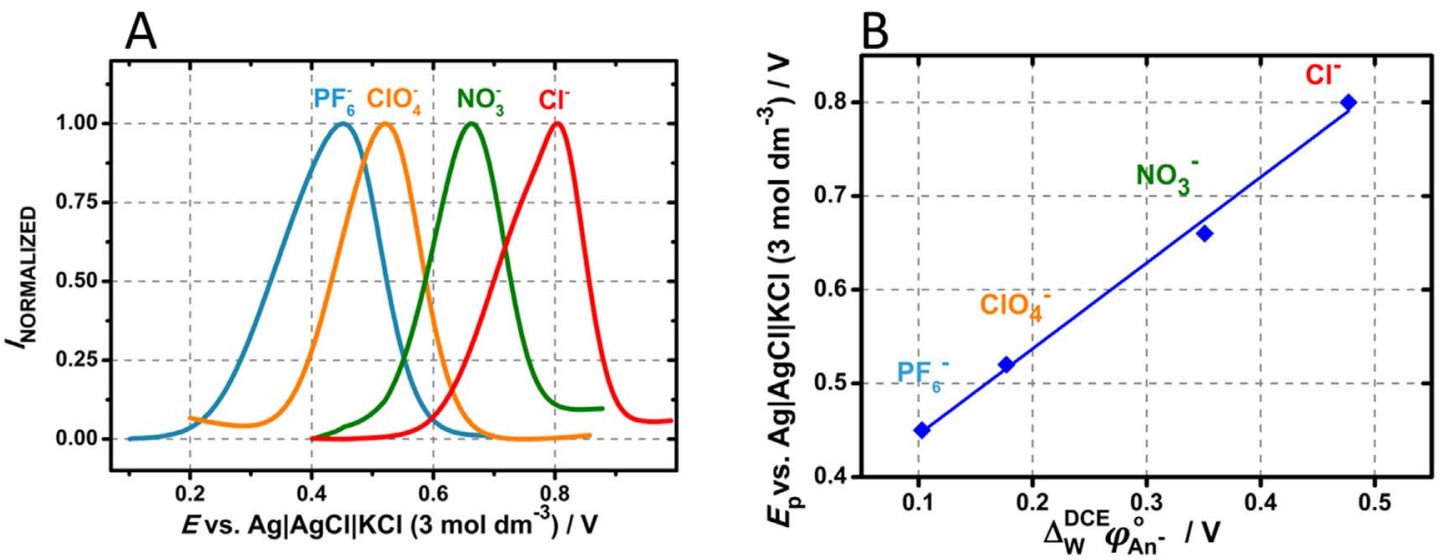

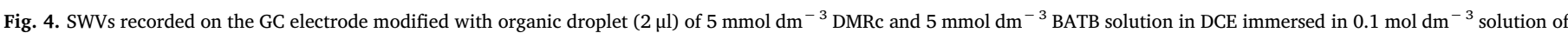

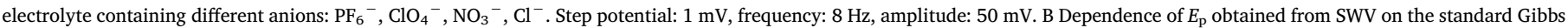
transfer potential for different anions at DCE $\mid \mathrm{W}$ interface $[24,26]$.

$\mathrm{DMRc}_{(\mathrm{DCE})}-\mathrm{e}+\mathrm{A}_{(\mathrm{w})}^{-} \leftrightarrow \mathrm{DMRc}_{(\mathrm{DCE})}^{+}+\mathrm{A}_{(\mathrm{DCE})}^{-}$

\subsection{SECM study of DMRc regeneration}

As it was shown above, DMRc can be completely consumed in the light-driven HER in the organic phase. To increase the efficiency of the reaction, DMRc has to be regenerated electrochemically by reduction of $\mathrm{DMRc}^{+}$, ensuring continuity of the two-phase process. For this purpose, SECM based setup with two Pt electrodes placed opposite one another at a distance of $50 \mu \mathrm{m}$ with liquid|liquid interface in between (Fig. 5) was applied [26].

The experiment was performed in a way that first, the aqueous phase was poured into the electrochemical cell. The upper Pt microelectrodes $(\varphi=25 \mu \mathrm{m})$ served as a SECM tip, another one $(\varphi=100 \mu \mathrm{m})$ was mounted to a manually positionable holder. The exact position of the bottom electrode was found by recording the approach curve with the upper electrode and performing lateral SECM scanning. Once the position of the bottom electrode was determined, the tip was raised up to a known distance. The organic phase was added in such a manner that its level was fixed above the bottom Pt electrode (while the upper electrode was still in the water solution). To position the liquid|liquid interface to obtain only a thin layer above the bottom electrode surface, the organic phase was carefully pumped out from the cell by a syringe pump. During pumping, a constant potential of $0.3 \mathrm{~V}$ was applied to the bottom electrode and the anodic current transient due to DMRc oxidation was recorded (Fig. 6). As shown in Fig. 6A, the measured current decreases as the distance of the bottom electrode to

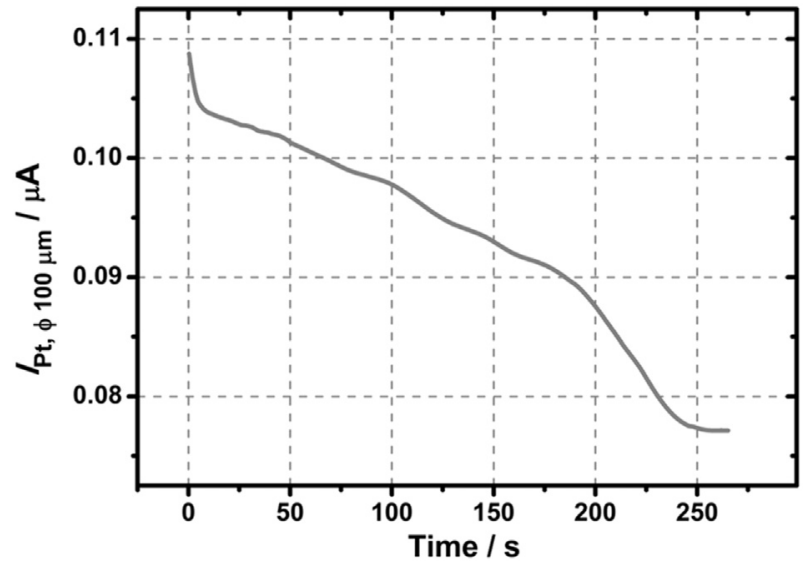

Fig. 6. Current transient recorded at the Pt microelectrode $(100 \mu \mathrm{m}$ diameter) at $0.3 \mathrm{~V}$ during pumping the organic phase out of the electrochemical cell.

the liquid|liquid interface decreases upon pumping. This is similar to hindered diffusion resulting in negative feedback in a typical SECM experiment. The pumping was terminated when the current dropped to $77 \mathrm{nA}$ (after 230 s). Using the Cornut and Lefrou expression [27] and taking 5 for RG (ratio of the disk electrode radius to the radius of glass), and $10^{-9}(\approx 0)$ for standard heterogeneous rate constant, the distance between DCE $\mid \mathrm{W}$ interface and the bottom Pt microelectrode was calculated to be $80 \mu \mathrm{m}$.

Next, the SECM tip was moved downwards to the bottom electrode

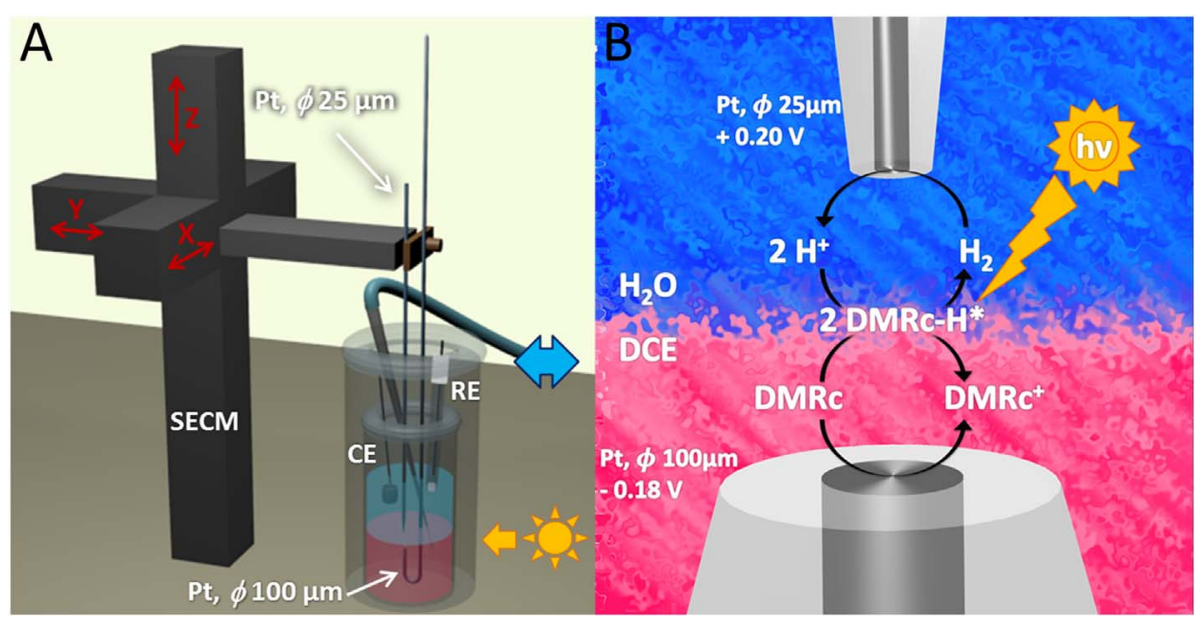

Fig. 5. A Scheme of SECM setup used for the study of DMRc regeneration with two Pt microelectrodes placed near ITIES. The blue double arrow shows the connection to the syringe pump that controls the position of liquid|liquid interface. The cell is inserted into a larger glass beaker filled with Ar to provide anaerobic conditions. B Reaction scheme. (For interpretation of the references to colour in this figure legend, the reader is referred to the web version of this article.) 
so the distance between them was $50 \mu \mathrm{m}$. It is important to notice that the approaching tip may cause ITIES deformation or when the tip breaks through the ITIES, a thin aqueous film can adhere to the electrode surface, even if it seems that the whole electrode is immersed in the organic phase [28]. The position of DCE $\mid W$ interface between the two microelectrodes was also confirmed by recording cyclic voltammograms at each electrode, i.e. the voltammogram recorded at the bottom electrode showed anodic wave due to DMRc oxidation in DCE (similar to presented in Fig. 3A), whereas voltammogram recorded on the upper SECM tip was similar to that shown on Fig. 3B.

Once the two electrodes were assembled in close vicinity to the DCE $\mid \mathrm{W}$ interface, photogenerated $\mathrm{H}_{2}$ was detected at the upper electrode, whereas on the bottom Pt electrode, continuous regeneration of $\mathrm{DMRc}^{+}$was carried out. The SECM tip was scanning in an aqueous solution above fixed bottom Pt electrode. The SECM tip was polarized at $0.20 \mathrm{~V}$, which allows diffusion-controlled oxidation of $\mathrm{H}_{2}$ in the aqueous phase, while the bottom Pt electrode $(100 \mu \mathrm{m}$ diameter) was polarized at $-0.18 \mathrm{~V}$, which corresponds to the reduction of $\mathrm{DMRc}^{+}$in DCE phase (Fig. 5B).

Only under light exposure with continuous regeneration increase of the tip current above the bottom electrode is seen, due to $\mathrm{H}_{2}$ oxidation. In control experiments carried out in darkness with or without DMRc regeneration, no such change was seen (Fig. 7). It shows that the electron donor regeneration at the Pt microelectrode placed in the organic phase results in an increase in $\mathrm{H}_{2}$ photogeneration and increases the efficiency of the HER under light illumination.

In order to estimate $\mathrm{H}_{2}$ concentration above the ITIES in the proximity of the bottom electrode and the $\mathrm{H}_{2}$ flux, a cross section above the centre of the SECM image in Fig. 7A has been extracted (Fig. 8). The resulting profile has been fitted to the following equations:

$i_{\mathrm{T}}=4 \mathrm{n} F D\left(\mathrm{H}_{2}\right) r_{\mathrm{T}}\left[\mathrm{H}_{2}\right]_{\mathrm{S}} \zeta$

$\zeta=\frac{2}{\pi} \arctan \frac{\sqrt{2} r_{\mathrm{S}}}{\sqrt{\left(\Delta x^{2}+d^{2}-r_{\mathrm{S}}^{2}\right)+\sqrt{\left(\Delta x^{2}+d^{2}-r_{\mathrm{S}}^{2}\right)^{2}+4 d^{2} r_{\mathrm{S}}^{2}}}}$

These equations were earlier developed for diffusion at an isolated disk-shaped pore [29,30], where $n=2$ is the number of transferred electrons from the microelectrode per $\mathrm{H}_{2}$ molecule, $D\left(\mathrm{H}_{2}\right)$ $=4.5 \times 10^{-5} \mathrm{~cm}^{2} \mathrm{~s}^{-1} \quad[31]$ is the diffusion coefficient of $\mathrm{H}_{2}$, $r_{\mathrm{T}}=12.5 \mu \mathrm{m}$ is the microelectrode radius, $r_{\mathrm{S}}$ is effective radius of the locus of effective HER at the ITIES, $\left[\mathrm{H}_{2}\right]_{\mathrm{S}}$ is the additional concentration of $\mathrm{H}_{2}$ at this locus, and $\zeta$ is a dimensionless factor describing the decrease of $\mathrm{H}_{2}$ concentration as a function of the lateral distance $\Delta x=x-x_{0}$ and the vertical distance $d$ from the centre of the silicate spot. Non-linear curve fitting (Fig. 8) yields the following adjustable parameters: $4 \mathrm{n} F D r_{\mathrm{T}}\left[\mathrm{H}_{2}\right]_{\mathrm{S}}=122( \pm 1) \mathrm{pA}, x_{0}=135.5( \pm 0.1) \mu \mathrm{m}$, $d=8.1( \pm 0.3) \mu \mathrm{m}, r_{\mathrm{S}}=36.9( \pm 0.2) \mu \mathrm{m}, i_{\text {offset }}=26( \pm 1) \mathrm{pA}$.

The value of $r_{\mathrm{S}}$ is smaller than that of the bottom electrode $(50 \mu \mathrm{m})$

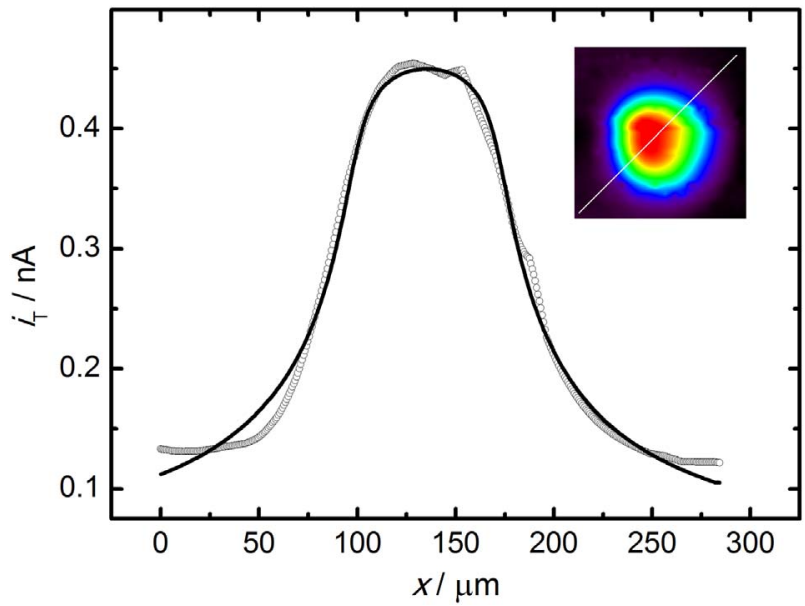

Fig. 8. Extracted profile along the white line in the inset and fits to Eqs. (4) and (5). Circles - experimental data, solid line - fitted curve. For more details see the text and the caption to Fig. 7.

due to the fact that it was positioned $80 \mu \mathrm{m}$ below the ITIES, and a part of regenerated DMRc diffuse towards DCE phase bulk. The offset current is a consequence of the presence of $\mathrm{H}_{2}$ traces in the system. HER occurs at the entire ITIES surface. However, at substantially lower rate than above the electrode at which DMRc is regenerated. The additional hydrogen surface concentration $\left[\mathrm{H}_{2}\right]_{\mathrm{S}}$ can be estimated as $2.8 \mu \mathrm{mol} \mathrm{dm}{ }^{-3}$. From this value, the flux $\Omega$ of $\mathrm{H}_{2}$ from the locus of effective HER at the ITIES [30]:

$\Omega=4 D\left(\mathrm{H}_{2}\right) r_{\mathrm{S}}\left[\mathrm{H}_{2}\right]_{\mathrm{S}}$

can be calculated as ca. $1.9 \times 10^{-15} \mathrm{~mol} \mathrm{~s}^{-1}$. The current recorded at the bottom electrode (DMRc regeneration) during SECM scanning was stable $i_{\mathrm{S}} \approx-5 \mathrm{nA}$. Using the Faraday laws and assuming $100 \%$ efficiency of the HER (Eq. (1)) from the regenerated DMRc one can calculate contribution of DMRc regeneration to the flux of hydrogen as $\sim 2.6 \times 10^{-14} \mathrm{~mol} \mathrm{~s}^{-1}$. This value is more than one order of magnitude larger than the hydrogen flux estimated by SECM in aqueous phase. This is due to the fact that only a fraction $(<10 \%)$ of $\mathrm{H}_{2}$ generated in DCE phase is transferred to aqueous phase. It is in accordance with our earlier considerations based on higher solubility of $\mathrm{H}_{2}$ in DCE than in water and slightly lower viscosity of DCE [22].

The SECM experiment described above is an example of a generation-collection mode approach from the side of the scanning tip, which probes $\mathrm{H}_{2}$ generated at the liquid|liquid interface. Amperometric microprobe oxidizes $\mathrm{H}_{2}$ to protons, which constitute additional flux of substrate for HER occurring at the ITIES. Due to high $\mathrm{H}^{+}$concentration in aqueous phase $\left(0.1 \mathrm{~mol} \mathrm{dm}^{-3} \mathrm{HClO}_{4}\right)$, a contribution of feedback to
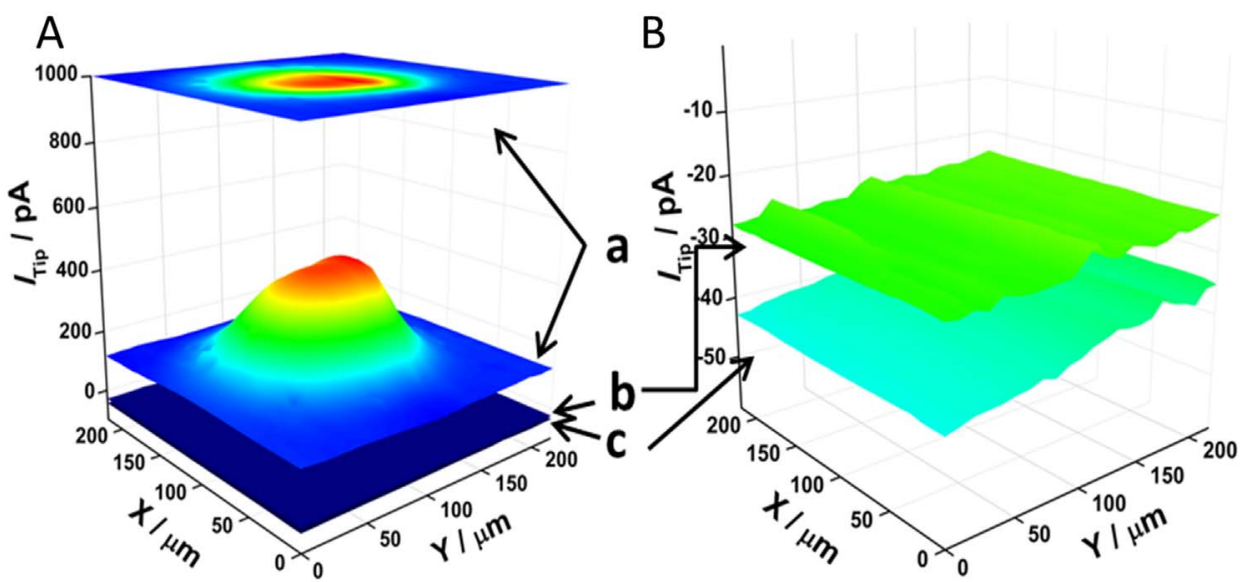

Fig. 7. A Tip current $\left(I_{\text {Tip }}\right)$ measured at $0.20 \mathrm{~V}$, in the aqueous solution above the bottom Pt electrode $(100 \mu \mathrm{m}$ diameter) polarized to $-0.18 \mathrm{~V}$ (i.e. with DMRc regeneration) (a) under UV light exposure, (b) in darkness and (c) in darkness without potential applied to the bottom electrode. The organic phase contained $5 \mathrm{mmol} \mathrm{dm}^{-3} \mathrm{DMRc}$ and $5 \mathrm{mmol} \mathrm{dm}^{-3}$ BATB. The Pt tip was placed in the water phase, containing $0.1 \mathrm{~mol} \mathrm{dm}^{-3} \mathrm{HClO}_{4}$, and $5 \mathrm{mmol} \mathrm{dm}^{-3}$ LiTB. The distance between the microelectrodes was $50 \mu \mathrm{m}$. Tip lateral velocity was $50 \mu \mathrm{m} \mathrm{s}^{-1}$. All measurements were made under an anaerobic condition. B Images $b$ and $c$ from figure A with enlarged current scale. 
measured tip current is negligible. Applied bi-potentiostatic system assures that the ITIES is not electrically polarized as in conventional ITIES research with four-electrode system. Bi-potentiostatic approach here introduces only minor local chemical polarization of ITIES caused by alteration of $\left[\mathrm{DMRc}^{+}\right] /[\mathrm{DMRc}]$ ratio in the vicinity of the microelectrode positioned in organic phase. These results clearly show that HER occurs at the entire illuminated ITIES and is effectively accelerated by electron donor regeneration.

\section{Conclusions}

In this work, we have demonstrated electrochemical regeneration of DMRc electron donor in DCE $\mid W$ two-phase system, where light-driven hydrogen evolution occurs. By using colourimetry, potentiometry and voltammetry techniques, we have identified oxidation of DMRc to $\mathrm{DMRc}^{+}$, and reduction of protons to $\mathrm{H}_{2}$. Experiments performed in the dark with droplet-modified electrodes revealed that electrode reactions of DMRc are coupled to reversible anion transfer processes across liquid|liquid boundary. To re-reduce $\mathrm{DMRc}^{+}$during the two-phase photoreaction, we have applied SECM setup with two microelectrodes located oppositely to the DCE $\mid \mathrm{W}$ interface. As a result of DMRc regeneration, the electron donor is not sacrificial anymore and the biphasic system can be further developed towards continuous hydrogen production system. It is worth to mention that fast electroregeneration of DMRc for spontaneous light-driven HER at the liquid|liquid interface is carried out at potential less negative $(-0.18 \mathrm{~V})$ than oxidation of $\mathrm{H}_{2}$ at Pt microelectrode $(-0.2 \mathrm{~V})$. This justifies applicability of DMRc electroregeneration for its application as electron donor for hydrogen evolution.

\section{Acknowledgements}

Project "PSPB-035/2010: Electrocatalysis at Droplets" was supported by a grant from Switzerland through the Swiss Contribution to the enlarged European Union.

\section{References}

[1] U. Mueller-Westerhoff, A. Nazzal, Ferrocenophanes as effective catalysts in the photoelectrochemical hydrogen evolution from acidic aqueous media, J. Am. Chem. Soc. 106 (1984) 5381-5382, http://dx.doi.org/10.1021/ja00330a074.

[2] U. Koelle, Transition metal catalyzed proton reduction, New J. Chem. 16 (1992) 157-169.

[3] U. Koelle, S. Paul, Electrochemical reduction of protonated cyclopentadienylcobalt phosphine complexes, Inorg. Chem. 25 (1986) 2689-2694, http://dx.doi.org/10. 1021/ic00236a007.

[4] U. Koelle, P.P. Infelta, M. Graetzel, Kinetics and mechanism of the reduction of protons to hydrogen by cobaltocene, Inorg. Chem. 27 (1988) 879-883.

[5] G.T. Baxley, A.A. Avey, T.M. Aukett, D.R. Tyler, Photoactivation of water by $\mathrm{Cp}_{2}{ }_{2} \mathrm{Mo}$ and photochemical studies of $\mathrm{Cp}_{2} \mathrm{MoO}$. Investigation of a proposed water-splitting cycle and preparation of a water-soluble molybdocene dihydride, Inorg. Chim. Acta 300-302 (2000) 102-112, http://dx.doi.org/10.1016/S0020-1693(99)00541-1.

[6] H. Kunkely, A. Vogler, Water splitting by light with osmocene as photocatalyst, Angew. Chem. Int. Ed. 48 (2009) 1685-1687, http://dx.doi.org/10.1002/anie. 200804712.

[7] L. Rivier, P. Peljo, L.A.C. Vannay, G.C. Gschwend, M.A. Méndez, C. Corminboeuf, M.D. Scanlon, H.H. Girault, Photoproduction of hydrogen by decamethylruthenocene combined with electrochemical recycling, Angew. Chem. Int. Ed. 56 (2017) 2324-2327, http://dx.doi.org/10.1002/anie.201610240.

[8] L. Rivier, T.J. Stockmann, M.A. Méndez, M.D. Scanlon, P. Peljo, M. Opallo, H.H. Girault, Decamethylruthenocene hydride and hydrogen formation at liquid|liquid interfaces, J. Phys. Chem. C 119 (2015) 25761-25769, http://dx.doi. org/10.1021/acs.jpcc.5b08148.

[9] L.J. Rivier, Photoproduction of Hydrogen by Decamethylruthenocene, Ecole Polytechnique Fédérale de Lausanne, 2017, http://dx.doi.org/10.5075/EPFLTHESIS-7690.

[10] I. Hatay, B. Su, F. Li, R. Partovi-Nia, H. Vrubel, X. Hu, M. Ersoz, H.H. Girault,
Hydrogen evolution at liquid-liquid interfaces, Angew. Chem. Int. Ed. Eng. 48 (2009) 5139-5142, http://dx.doi.org/10.1002/anie.200901757.

[11] M.A. Mendez, R. Partovi-Nia, I. Hatay, B. Su, P.Y. Ge, A. Olaya, N. Younan, M. Hojeij, H.H. Girault, Molecular electrocatalysis at soft interfaces, Phys. Chem Chem. Phys. 12 (2010) 15163-15171, http://dx.doi.org/10.1039/c0cp00590h.

[12] B. Su, I. Hatay, P.Y. Ge, M. Mendez, C. Corminboeuf, Z. Samec, M. Ersoz, H.H. Girault, Oxygen and proton reduction by decamethylferrocene in non-aqueous acidic media, Chem. Commun. 46 (2010) 2918-2919, http://dx.doi.org/10.1039/ b926963k.

[13] W. Adamiak, J. Jedraszko, O. Krysiak, W. Nogala, J.C. Hidalgo-acosta, H.H. Girault, M. Opallo, Hydrogen and hydrogen peroxide formation in trifluorotoluene - water biphasic systems, J. Phys. Chem. C 118 (2014) 23154-23161, http://dx.doi.org/10. 1021/jp507310d.

[14] P. Ge, M.D. Scanlon, P. Peljo, X. Bian, H. Vubrel, A. O'Neill, J.N. Coleman, M. Cantoni, X. Hu, K. Kontturi, B. Liu, H.H. Girault, Hydrogen evolution across nano-Schottky junctions at carbon supported MoS2 catalysts in biphasic liquid systems, Chem. Commun. 48 (2012) 6484-6486, http://dx.doi.org/10.1039/ c2cc31398g.

[15] M.D. Scanlon, X. Bian, H. Vrubel, V. Amstutz, K. Schenk, X. Hu, B. Liu, H.H. Girault, Low-cost industrially available molybdenum boride and carbide as "platinum-like" catalysts for the hydrogen evolution reaction in biphasic liquid systems, Phys. Chem. Chem. Phys. 15 (2013) 2847-2857, http://dx.doi.org/10.1039/c2cp44522k.

[16] L. Liao, J. Zhu, X. Bian, L. Zhu, M.D. Scanlon, H.H. Girault, B. Liu, MoS 2 formed on mesoporous graphene as a highly active catalyst for hydrogen evolution, Adv. Funct. Mater. 23 (2013) 5326-5333, http://dx.doi.org/10.1002/adfm.201300318.

[17] P. Ge, A.J. Olaya, M.D. Scanlon, I. Hatay Patir, H. Vrubel, H.H. Girault, Photoinduced biphasic hydrogen evolution: decamethylosmocene as a light-driven electron donor, ChemPhysChem 14 (2013) 2308-2316, http://dx.doi.org/10.1002/ cphc. 201300122.

[18] X. Bian, M.D. Scanlon, S. Wang, L. Liao, Y. Tang, B. Liu, H.H. Girault, Floating conductive catalytic nano-rafts at soft interfaces for hydrogen evolution, Chem. Sci. 4 (2013) 3432-3441, http://dx.doi.org/10.1039/c3sc51290h.

[19] I. Hatay, P.Y. Ge, H. Vrubel, X. Hu, H.H. Girault, C. Corminboeuf, Z. Samec, H.H. Girault, J.-M. Barbe, M. Ersoz, S. Záliš, Z.k. Samec, H.H. Girault, Hydrogen evolution at polarised liquid/liquid interfaces catalyzed by molybdenum disulfide, Energy Environ. Sci. 4 (2011) 4246-4251, http://dx.doi.org/10.1039/c1ee01996a.

[20] A.J. Olaya, M.A. Méndez, F. Cortes-Salazar, H.H. Girault, Voltammetric determination of extreme standard Gibbs ion transfer energy, J. Electroanal. Chem. 644 (2010) 60-66, http://dx.doi.org/10.1016/j.jelechem.2010.03.030.

[21] Z. Samec, N. Eugster, D.J. Fermín, H.H. Girault, A generalised model for dynamic photocurrent responses at dye-sensitised liquid|liquid interfaces, J. Electroanal. Chem. 577 (2005) 323-337, http://dx.doi.org/10.1016/j.jelechem.2004.12.009.

[22] J. Jedraszko, W. Nogala, W. Adamiak, H.H. Girault, M. Opallo, Scanning electrochemical microscopy determination of hydrogen flux at liquid|liquid interface with potentiometric probe, Electrochem. Commun. 43 (2014) 22-24, http://dx.doi.org/ 10.1016/j.elecom.2014.03.006.

[23] S.A. Khan, S. Duraiswamy, Controlling bubbles using bubbles-microfluidic synthesis of ultra-small gold nanocrystals with gas-evolving reducing agents, Lab Chip 12 (2012) 1807-1812, http://dx.doi.org/10.1039/c2lc21198j.

[24] S. Komorsky-Lovric, M. Lovric, F. Scholz, Cyclic voltammetry of decamethylferrocene at the organic liquid aqueous solution graphite three-phase junction, J. Electroanal. Chem. 508 (2001) 129-137.

[25] W. Adamiak, M. Opallo, Electrochemical redox processes of fullerene C60 and decamethylferrocene dissolved in cast 1,2-dichlorobenzene film in contact with aqueous electrolyte, J. Electroanal. Chem. 643 (2010) 82-88, http://dx.doi.org/10. 1016/j.jelechem.2010.03.005.

[26] J. Jedraszko, W. Nogala, W. Adamiak, E. Rozniecka, I. Lubarska-Radziejewska, H.H. Girault, M. Opallo, Hydrogen peroxide generation at liquid|liquid interface under conditions unfavorable for proton transfer from aqueous to organic phase, $\mathrm{J}$. Phys. Chem. C 117 (2013) 20681-20688, http://dx.doi.org/10.1021/jp406422d.

[27] R. Cornut, C. Lefrou, New analytical approximation of feedback approach curves with a microdisk SECM tip and irreversible kinetic reaction at the substrate, J. Electroanal. Chem. 621 (2008) 178-184, http://dx.doi.org/10.1016/j.jelechem. 2007.09.021.

[28] C. Wei, A.J. Bard, M.V. Mirkin, Scanning electrochemical microscopy. 31. Application of SECM to the study of charge transfer processes at the liquidliquid interface, J. Phys. Chem. 99 (1995) 16033-16042.

[29] Y. Saito, A theoretical study on the diffusion current at the stationary electrodes of circular and narrow band types, Rev. Polarogr. 15 (1968) 177-187 https://scholar. google.es/citations? view op $=$ view citation $\& \mathrm{hl}=$ ja\&user $=$ oTK7FjoAAAAJ\& citation_for_view = oTK7FjoAAAAJ:UHK10RUVsp4C (accessed September 6, 2017).

[30] B.D. Bath, R.D. Lee, H.S. White, E.R. Scott, Imaging molecular transport in porous membranes. Observation and analysis of electroosmotic flow in individual pores using the scanning electrochemical microscope, Anal. Chem. 70 (1998) 1047-1058, http://dx.doi.org/10.1021/ac971213i.

[31] A.F.A.F. Mazarei, O.C.O.C. Sandall, Diffusion coefficients for helium, hydrogen, and carbon dioxide in water at $25^{\circ} \mathrm{C}$, AICHE J. 26 (1980) 154-157, http://dx.doi.org/ 10.1002/9780470995327.ch191. 